\title{
Meta-analysis identifies global and regional change during Cretaceous Ocean Anoxic Event 2
}

\author{
MAOLI VIZCAÍNO ${ }^{1}$, INESSA YURCHENKO ${ }^{1}$, ROB $^{2}$ \\ FORKNER $^{2}$, ANDREA FILDANI ${ }^{2}$, JEREMY D. OWENS ${ }^{3}$, \\ LARAMIE E. DUNCAN ${ }^{4}$, ERIK A. SPERLING ${ }^{1}$ \\ ${ }^{1}$ Stanford University, Dept. of Geological Sciences, Stanford \\ University, Stanford, CA, USA; mnviz@stanford.edu \\ ${ }^{2}$ The Deep Time Institute, Austin, Texas, USA \\ ${ }^{3}$ Dept. of Earth, Ocean and Atmospheric Science, Florida \\ State University, Tallahassee, FL, USA \\ ${ }^{4}$ Dept. of Psychiatry and Behavioural Sciences, Stanford \\ University, Stanford, CA, USA
}

The Cenomanian-Turonian Ocean Anoxic Event (OAE-2) has long been recognized in the sedimentary record, but questions remain about the magnitude of change for individual localities versus the global extent of the event. Meta-analysis (the quantitative synthesis of research results) is an approach that has gained widespread use in other fields to test the support for a hypothesis with the published body of research, but this approach has not been utilized in sedimentary geochemistry. Meta-analysis uses effect sizes from individual studies (in this case, stratigraphic sections/drill cores), weighted by the inverse variance of the effect size estimate, to achieve an overall, directional measure of mean change. It is thus well-suited to extracting global and regional signals from multiple sections - each of which may be biased in different ways - and from studies with different sampling intensities. As OAE-2 is one of the best-sampled events in the sedimentary record, it is a logical first application of meta-analysis in Earth history studies.

Here, we first report new iron, carbon, and trace metal analyses from three drill cores spanning the OAE- 2 event in Colombia and the USA and then combine these data with published global data. Initial meta-analysis shows that across all sites there is a significant increase in weight percent total organic carbon (TOC) during the positive carbon isotope excursion associated with OAE-2, but that the pattern is regionally heterogeneous. Specifically, TOC increases dramatically during OAE-2 at sites in the Atlantic and western Tethys oceans, but there is no significant change in the Western Interior Seaway and Pacific Ocean. Ongoing meta-analyses of redox geochemical data will be used to test changes in redox state of the global ocean and between ocean basins. These results indicate that oceans are spatially and temporally dynamic even during a 'global' event such as an OAE, and highlight the utility of meta-analysis in elucidating patterns of complex enviromental change. 